\title{
Phosphorylation-dependent regulation of the F-BAR protein Hof 1 during cytokinesis
}

\author{
Franz Meitinger, ${ }^{1}$ Martin E. Boehm, ${ }^{2}$ Astrid Hofmann, ${ }^{1}$ Birgit Hub ${ }^{3}$ Hanswalter Zentgraf, ${ }^{3}$ \\ Wolf D. Lehmann, ${ }^{2}$ and Gislene Pereira ${ }^{1,4}$ \\ ${ }^{1}$ Molecular Biology of Centrosomes and Cilia Unit, DKFZ-ZMBH Alliance, German Cancer Research Center, 69120 Heidelberg, \\ Germany; ${ }^{2}$ Molecular Structure Analysis, German Cancer Research Center, 69120 Heidelberg, Germany; ${ }^{3}$ Department of Tumor \\ Virology, German Cancer Research Center, 69120 Heidelberg, Germany
}

Spatial and timely coordination of cytokinesis is crucial for the maintenance of organelle inheritance and genome integrity. The mitotic exit network (MEN) pathway controls both the timely initiation of mitotic exit and cytokinesis in budding yeast. Here we identified the conserved F-BAR protein Hof1 as a substrate of the MEN kinase complex Dbf2-Mob1 during cytokinesis. We show that polo-like kinase Cdc5 first phosphorylates Hof1 to allow subsequent phosphorylation by Dbf2-Mob1. This releases Hof1 from the septin ring and facilitates Hof1 binding to the medial actomyosin ring (AMR), where Hof1 promotes AMR contraction and membrane ingression. Domain structure analysis established that the central, unstructured, region of Hof1, named the ring localization sequence (RLS), is sufficient to mediate Hof1's binding to the medial ring in a cell cycle-dependent manner. Genetic and functional data support a model in which Dbf2-Mob1 regulates Hof1 by inducing domain rearrangements, leading to the exposure of the Hof1 RLS domain during telophase.

[Keywords: cell cycle; cytokinesis; mitotic exit network; Hof1; Dbf2-Mob1; F-BAR]

Supplemental material is available for this article.

Received December 30, 2010; revised version accepted February 28, 2011.

Cytokinesis is the process by which mother and daughter cells become physically separated from one another after the completion of mitosis. In yeast and higher eukaryotes, cytokinesis involves an actomyosin ring (AMR) whose contraction drives cleavage furrow formation and/or membrane ingression at the site of cell division (Bi 2001; Balasubramanian et al. 2004; Barr and Gruneberg 2007). The coordination and successful completion of cytokinesis is important to prevent polyploidy, which could cause cell death and tumorigenesis (Sagona and Stenmark 2010).

F-BAR proteins localize to the division sites of organisms as diverse as yeast and humans (Fankhauser et al. 1995; Spencer et al. 1997; Lippincott and Li 1998). Their ability to connect membrane binding and deformation with the actin cytoskeleton is highly suggestive of potential functions in cytokinesis (Aspenstrom 2009). In budding yeast, five F-BAR proteins have been identified. Of these, Hof 1 has the most prominent localization at the site of cell division (named the bud neck) (Lippincott and Li 1998). Hof1 is the homolog of PSTPIP1 in mammals (Spencer et al. 1997) and Cdc15 in fission yeast, which has a clearly established role in cytokinesis (Fankhauser et al. 1995). This F-BAR subfamily is characterized by an

${ }^{4}$ Corresponding author.

E-MAIL g.pereira@dkfz.de; FAX 49-6221-423450.

Article is online at http://www.genesdev.org/cgi/doi/10.1101/gad.622411.
N-terminal F-BAR domain followed by an unstructured region containing a PEST motif and a C-terminal SH3 domain (Aspenstrom et al. 2006). The SH3 domain of Hof1 is known to bind to a variety of different proteins via their PXXP-docking motifs (Tonikian et al. 2009), while the PEST motif is necessary for Hof1 degradation mediated by the SCF complex (Blondel et al. 2005).

Hof1 accumulates at the bud neck as soon as cells enter a new cell cycle. It colocalizes with the septin ring until late anaphase, when it shifts to the contractile AMR just before ring contraction (Vallen et al. 2000). Hof1 has been proposed to act as an inhibitor of cytokinesis. This view is supported by the fact that HOF1 overexpression or expression of a stabilized mutant version both inhibit cytokinesis (Blondel et al. 2005). However, deletion of HOF1 impairs AMR contraction and causes lethality in the absence of other cytokinetic components, implying that Hof1 also positively regulates cytokinesis.

Hof1 forms a complex with Inn1 and Cyk3, which coordinate AMR contraction with membrane ingression and primary septum formation (Sanchez-Diaz et al. 2008; Jendretzki et al. 2009; Nishihama et al. 2009). Hof1, Inn1, and Cyk3 are recruited sequentially to the AMR just before contraction. The timed assembly of this complex needs to be cell cycle-regulated in a temporal and spatial manner. Interestingly, the kinase Dbf2-in complex with its activator, Mob1-appears at the site of cell division 
just before AMR contraction and cytokinesis (Frenz et al. 2000; Yoshida and Toh-e 2001). Dbf2-Mob1 is a component of the mitotic exit network (MEN) signaling pathway (Bardin and Amon 2001). The recruitment of the Dbf2-Mob1 complex to the bud neck is dependent on the down-regulation of mitotic Cdk1 activity, and is thus subjected to strong cell cycle control (Hwa Lim et al. 2003). We showed previously that the recruitment and function of Inn 1 and Cyk3 to the AMR and the formation of the septum depend on the Dbf2-Mob1 complex (Meitinger et al. 2010). Nevertheless, a direct target for Dbf2-Mob1 at the bud neck remains to be identified. Interestingly, orthologs of Mob1 and Dbf2 in higher eukaryotes, known as Lats1/2 and Mob1, were reported to play a role in cytokinesis (Hammarton et al. 2005; Citterio et al. 2006; Yabuta et al. 2007). Thus, identifying how Dbf2-Mob1 regulates cytokinesis is of general importance.

Here, we show that the mitotic kinases Cdk1, Cdc5, and Dbf2-Mob1 all regulate Hof1 localization and function during cytokinesis. Phosphorylation of Hof1 by mitotic Cdk1 primes Hof 1 to recruit Cdc5. Cdc5 in turn phosphorylates Hof1 to create a binding site for Mob1. Dbf2-Mob1 then subsequently phosphorylates Hof1 and contributes to the relocation of Hof 1 from septins to the AMR. In parallel, we established that, while the F-BAR and SH3 domains direct Hof1 to the septin ring, the central unstructured region of Hof1 (referred to here as the ring localization sequence [RLS]) promotes Hof1 binding to the AMR in a cell cycle-dependent manner. We propose that the concerted action of mitotic kinases control Hof1 localization and function during cytokinesis.

\section{Results \\ Identification of the novel RLS of Hof1 as an $A M R$-binding domain}

Hof1 contains an $\mathrm{FCH}$ domain that is followed by a coiled-coil region at the $\mathrm{N}$ terminus /which together form the F-BAR domain) and an SH3 domain at its $\mathrm{C}$ terminus (Fig. 1A). The central region of Hofl (amino acids 200-599) is predicted to be unstructured. However, it contains a short coiled coil and a PEST sequence that is involved in the ubiquitin-mediated degradation of Hof1 (Blondel et al. 2005). To investigate the contribution of these different domains within Hof1 to its localization
A

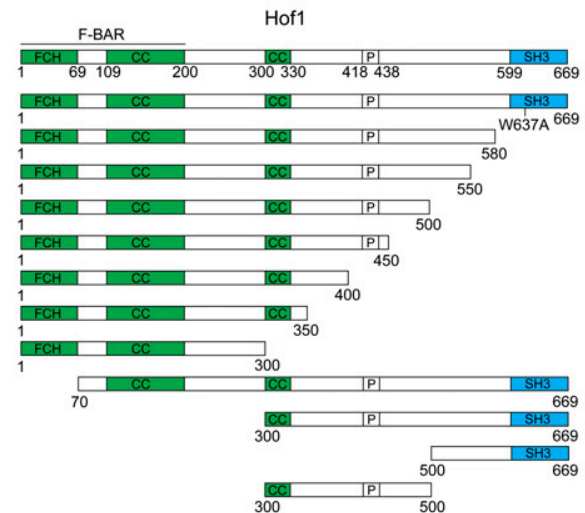

\begin{tabular}{|c|c|c|c|c|c|}
\hline 94 & 0 & 6 & 53 & 0 & 47 \\
\hline 0 & 91 & 9 & 0 & 0 & 100 \\
\hline 0 & 87 & 13 & 0 & 0 & 100 \\
\hline 0 & 89 & 11 & 0 & 0 & 100 \\
\hline 0 & 87 & 13 & 0 & 0 & 100 \\
\hline 0 & 100 & 0 & 0 & 100 & 0 \\
\hline 0 & 100 & 0 & 0 & 100 & 0 \\
\hline 0 & 100 & 0 & 0 & 100 & 0 \\
\hline 0 & 0 & 0 & 0 & 0 & 0 \\
\hline 0 & 18 & 6 & 0 & 0 & 75 \\
\hline 0 & 88 & 12 & 0 & 0 & 97 \\
\hline 0 & 0 & 0 & 0 & 0 & 0 \\
\hline 0 & 0 & 6 & 0 & 0 & 100 \\
\hline
\end{tabular}

B

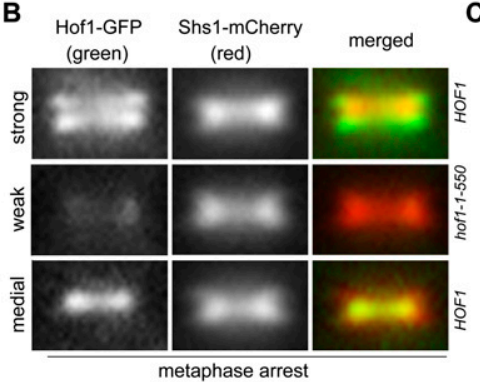

D

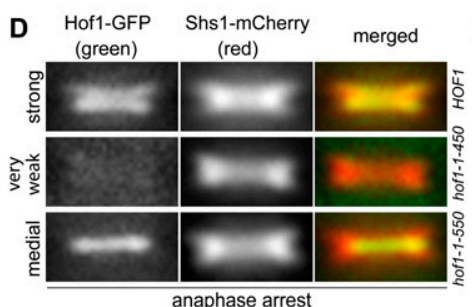

C
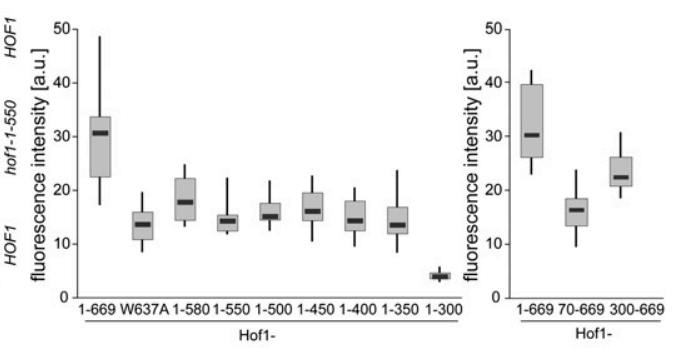

E

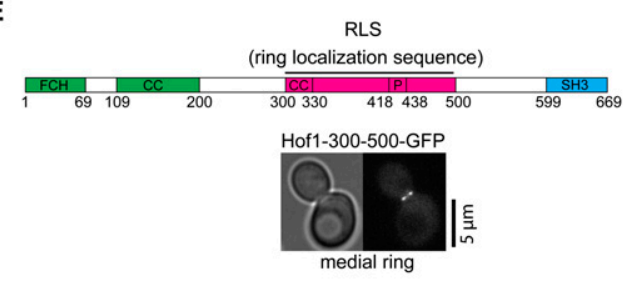

Figure 1. Domain analysis of Hof1 bud neck localization. (A) Schematic representation (numbers represent amino acid positions) and quantification of metaphaseand anaphase-arrested cells (percentage) carrying the indicated Hof 1 constructs. (FCH) FER/CIP4 homology; (CC) coiled coil; (SH3) SRC homology 3; (P) PEST sequence. " 0 " means no localization at the indicated bud neck region, yet protein levels were not decreased in comparison with wild-type Hof1 (see Supplemental Fig. S1). The cartoons represent the bud neck region showing "strong" and "weak" Hof1GFP signals associated with septins (double bars) or at the medial ring (single bar). $(B, D)$ Representative examples of Hof1-GFP signals at the bud neck in metaphase-arrested $(B)$ and anaphase-arrested $(D)$ cells, taken from the indicated cell backgrounds. $(C)$ Quantification of Hof1-GFP fluorescence intensity at the bud neck (in arbitrary units) in metaphase-arrested cells $(n=15$ per strain). (E) Schematic representation of the RLS region (pink) and a representative cell expressing HOF1-300-500-GFP. 
and function, endogenous $H O F 1$ was replaced by a series of HOF1 truncations fused to the green fluorescent protein (GFP) (Fig. 1A). Cells carried an additional gene fusion to mark the septin; the septin SHS1 fused to the monomeric fluorescent protein Cherry (Shs1-mCherry). For ease of comparison, the localization of Hof1-GFP was analyzed in cells arrested in either metaphase by adding nocodazole or anaphase by overexpressing a nondegradable form of the mitotic cyclin Clb2 (clb2 $\Delta D B)$ (Surana et al. 1993). In every case, this localization was later confirmed in cycling cells (Supplemental Fig. S1).

In metaphase-arrested cells, full-length Hof1-GFP formed a double ring that, in $94 \%$ of the cells, colocalized with Shs1-mCherry (Fig. 1A,B, top panel, "strong" septin staining). The association of Hof1-GFP with this Shs1mCherry ring was reduced but still clearly detectable following deletion of either the F-BAR (codons 1-200) or SH3 (codons 599-669) domains (Fig. 1A-C, "weak"), but was completely abolished by simultaneous deletion of both domains (Fig. 1A). The lack of bud neck recruitment was not due to a decrease in Hofl protein levels (Supplemental Fig. S1C). Further supporting a role of the SH3 domain, substitution of the highly conserved Trp 637, which is essential for the SH3 domain to bind to PXXP motifs with an alanine residue (W637A) (Supplemental Fig. S2), also decreased the colocalization of Hof1 with septins in metaphase (Fig. 1A-C). Thus, the F-BAR and SH3 domains have supporting functions in recruiting Hof1 to the septin ring in metaphase.

In late anaphase, full-length Hof1-GFP either colocalized with Shs1-mCherry (septin staining 53.4\%) (Fig. $1 \mathrm{~A}, \mathrm{D}$, top panel, "strong") or formed a discrete line within the medial part of the Shs1-mCherry ring (medial ring localization 46.6\%) (Fig. 1A,D, bottom panel, "medial"). The septin-like staining of anaphase cells was drastically reduced for Hof 1 constructs that lacked functional F-BAR or SH3 domains. However, these Hof1 mutants preferably localized to the medial ring, suggesting that the F-BAR and SH3 domains target Hof 1 to the septin ring, while a region between these domains targets Hof 1 to the medial ring. Consistently, Hof1-300-500-GFP, which lacks both the F-BAR and SH3 domains, bound exclusively to the medial ring in anaphase (Figs. 1A,E; Supplemental Fig. S3A-C). The shortening of this region either compromised (Hof1-400-500) or completely abolished (Hof1300-400) medial ring localization (Supplemental Fig. S3B). We concluded that the amino acids stretching from 300 to 500 within the unstructured part of Hof1 represent the minimal domain required for efficient localization of Hof1 to the medial ring in late anaphase. We refer to this region as the RLS.

In summary, our findings show that both the F-BAR and SH3 domains are important for Hof 1 septin localization. In contrast, the RLS recruits Hofl to the AMR in late anaphase.

\section{F-BAR and RLS domains support AMR contraction}

Hofl is a multifunctional protein. One important role executed by Hofl is the promotion of centripetal (sym- metric) AMR contraction (Nishihama et al. 2009). We established by electron microscopy that, in hof $1 \Delta$ cells, the primary septum was frequently formed in an asymmetric manner (Fig. 2A-C) and was mostly surrounded by a thick layer of secondary septal material (Fig. 2A-D). Defects in primary septum formation therefore account for asymmetric AMR contraction.

Hof1 binds to the essential protein Inn1, which is part of the AMR and is involved in primary septum formation (Sanchez-Diaz et al. 2008; Nishihama et al. 2009). To understand the role played by the different Hofl domains in AMR contraction and septum formation, we used livecell imaging. Because fusion of MYO1 to GFP caused growth sickness together with Hof 1 truncations, we analyzed the behavior of Inn1-GFP, as a marker for AMR contraction, in cells expressing wild-type and truncated HOF1 constructs (Fig. 2B-F). In wild-type cells, Inn1-GFP bound to the bud neck in a symmetric manner (covering the entire bud neck) (Fig. 2B, $90 \mathrm{sec}$ ) and finally contracted together with the AMR, forming a dot-like staining in the center of the bud neck (Fig. 2B, 240 and $270 \mathrm{sec}$ ). In line with a previous study (Nishihama et al. 2009), while Inn1GFP was able to bind to the bud neck in the absence of HOF1, Inn1-GFP contracted asymmetrically, and the contraction was significantly slower in hof $1 \Delta$ cells than in wild-type controls (Fig. 2C,G,H). The correlation between asymmetric Innl contraction and asymmetric septum formation observed by electron microscopy in hof1s cells means that Inn1-GFP can be used as marker for septum formation. We next analyzed the behavior of Inn1 in HOF1 mutants. Interestingly, deletion of the Hof 1 SH3 domain (Hof1-1-500) did not alter Inn1-GFP contraction patterns or rate even though it abolished the direct binding of Inn1 to Hof1 (Supplemental Fig. S2). Thus, the SH3 domain of Hof 1 is dispensable for the symmetric contraction of Inn1. In contrast, cells lacking SH3 and part of the RLS domain (Hof1-1-450) or the entire F-BAR domain (Hof1-300-669) phenocopied hof1s cells with respect to Inn1 behavior (Fig. 2E-H). Because fusion of INN1 to GFP caused growth sickness in hof1300-500 cells, we were unable to analyze the effect of Hof1 RLS (without F-BAR and SH3 domains) on Inn1 contraction. In conclusion, while the Hof1 SH3 domain is directly involved in binding to Inn1, only the F-BAR and RLS domains are essential for the promotion of centripetal Innl contraction during cytokinesis.

Hof1 is directly phosphorylated by Cdk1, Cdc5, and Dbf2 kinases

The cell cycle-dependent relocation of Hof1 in late mitosis prompted us to ask how Hofl is regulated. Although Hof 1 has been reported to be subjected to cell cycledependent phosphorylation (Vallen et al. 2000; Blondel et al. 2005), the identity of the kinases responsible for this phosphorylation has remained obscure. We therefore screened selected candidate kinases for a physical association with Hof1 using the yeast two-hybrid system. We found that Hof1 strongly interacted with Mob1, the regulatory subunit of Dbf2 kinase (Fig. 3A). Hof1 also 
A

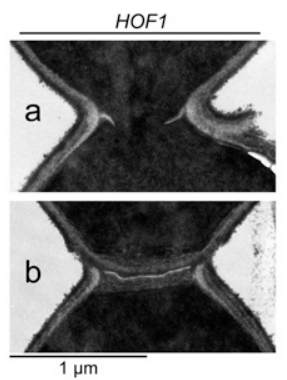

B

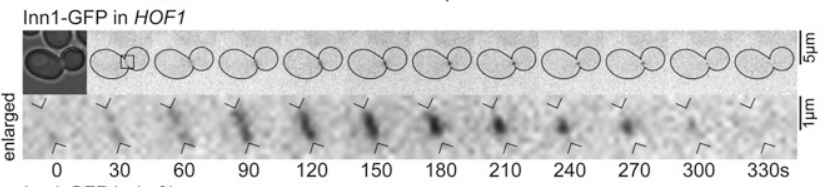

C Inn1-GFP in hof1 $\Delta$

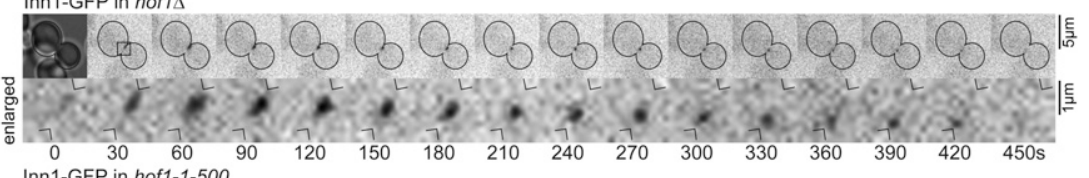

D

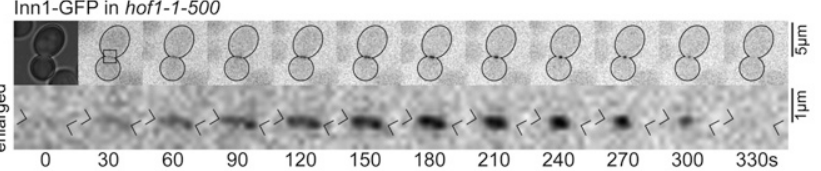

E

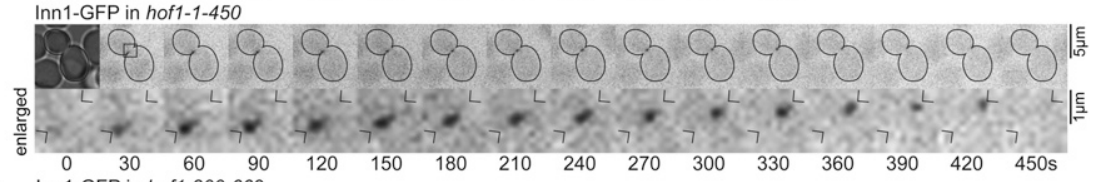

F

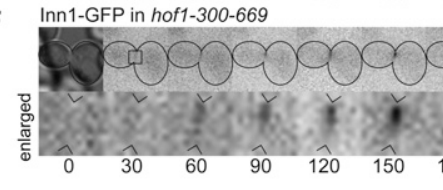

G
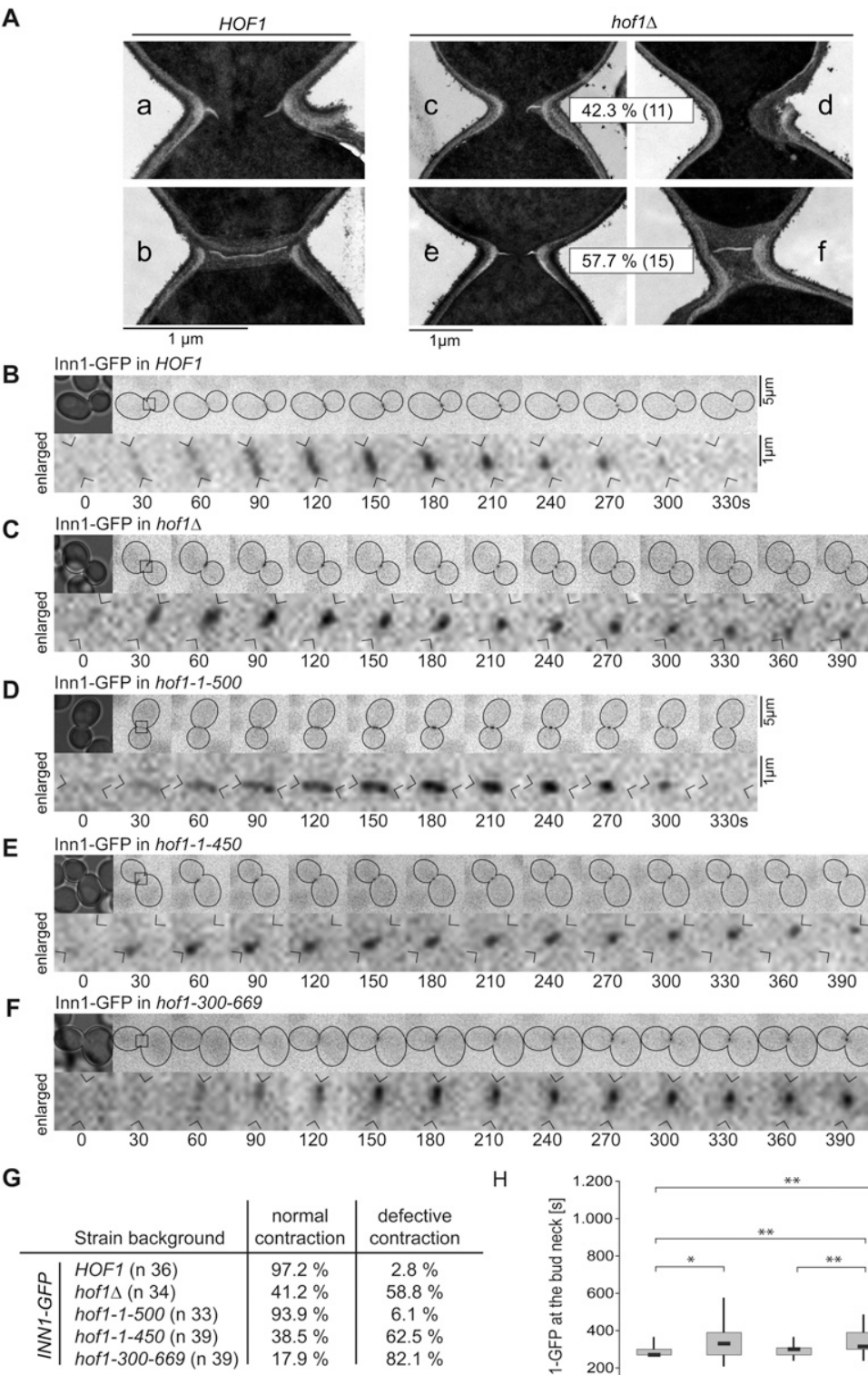
:

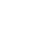

\section{(1)}


A
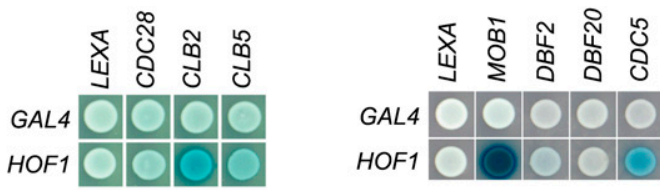

B
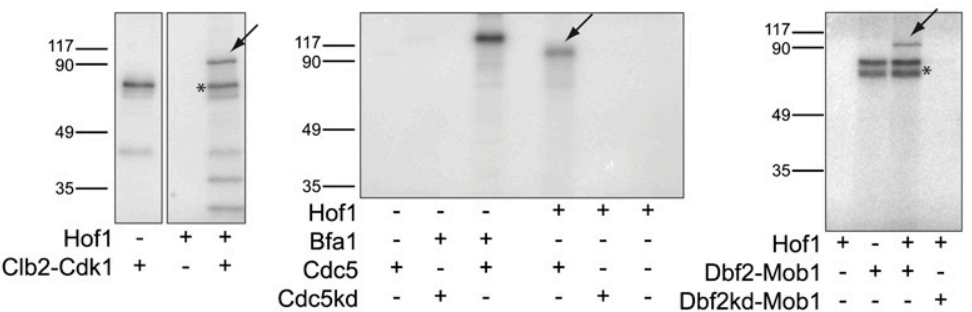

C
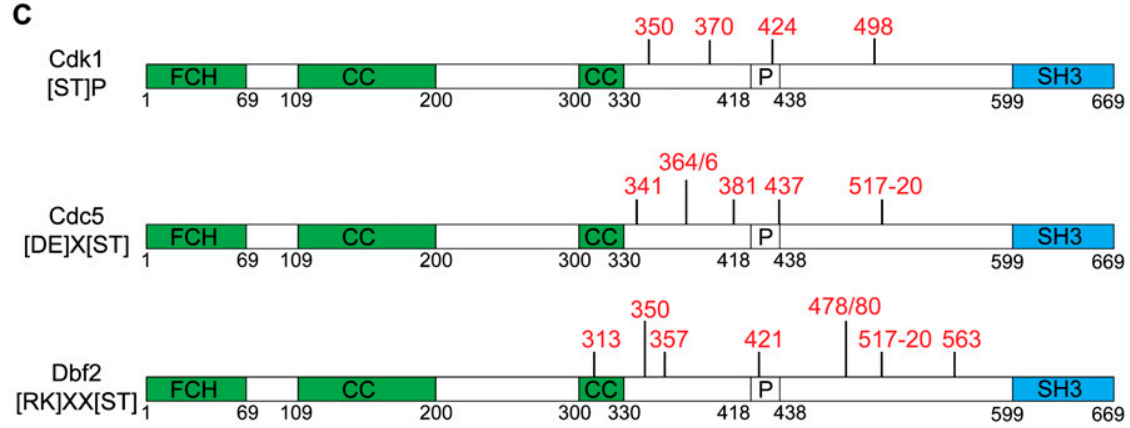

D

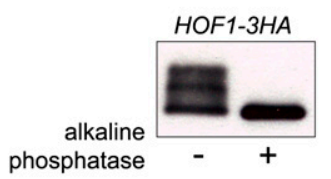

E

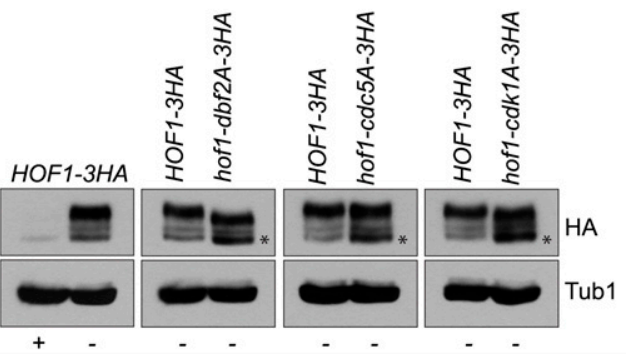

Figure 3. Hof1 is a substrate of the Clb2Cdk1, Cdc5, and Dbf2-Mob1 kinases. $(A)$ Yeast two-hybrid interaction between LexA and Gal4 gene fusions, as indicated. Development of a blue color indicates interaction. (B) Autoradiographs showing Hof1 phosphorylated by purified Clb2Cdk1, Cdc5, and Dbf2-Mob1 in vitro (arrows), but not by the corresponding kinasedead (kd) mutants. Asterisks mark the autophosphorylation of Clb2-Cdk1 and Dbf2-Mob1. Bfa1 served as positive control for Cdc5 activity. $(C)$ Schematic representation of Hof 1 phosphorylation sites identified by MS for Clb2-Cdk1, Cdc5, and Dbf2-Mob1 in vitro (depicted in red). Consensus sites are indicated for each kinase. Numbers denote amino acids positions. Hof1 domains are represented as in Figure 1A. (D) Immunoblot using anti-HA antibodies showing immunoprecipitated Hof13HA treated with alkaline phosphatase $(+)$ or buffer $(-)$. (E) Comparison analysis of the phosphorylation pattern of indicated Hof13HA constructs expressed in Gall-GRR1 cells upon depletion of $G R R 1$ by glucose addition $\left(G R R 1^{-}\right)$. Protein levels of Hof13HA in cells expressing GRR1 $\left(G R R 1^{+}\right)$are shown for comparison. Hof1-3HA was detected using anti-HA antibodies. Tubulin (Tub1) served as loading control. complex that targets phosphorylated forms of Hof 1 for degradation (Blondel et al. 2005). As Hofl is stabilized in grr1s cells, the incorporation of this mutation preserves the phosphorylated forms of Hof 1 that otherwise would be immediately targeted for destruction. Cells lacking Grr1 accumulated slow-migrating phosphorylated forms of Hof1 (Fig. 3D,E). The MS analysis revealed that the majority of the amino acids phosphorylated in vitro were also phosphorylated in vivo (Supplemental Table S1). Interestingly, some of the phosphorylation sites for Cdk1, Cdc5, and Dbf2 found in vivo overlapped and were phosphorylated by more than one kinase in vitro (Supplemental Table S1). For example T350 was phosphorylated by both Clb2-Cdk1 and Dbf2-Mob1, while S517 was targeted by Cdc5 and Dbf2-Mob1. It therefore seems likely that redundant mechanisms exist in vivo to ensure efficient phosphorylation of Hof1 at these sites.

We next investigated the contribution of Clb2-Cdk1, Cdc5, and Dbf2-Mob1 to phosphorylation at specific sites in vivo. To assess Cdk1 phosphorylation, we generated a phospho-specific antibody against Ser 424 (anti-S424-P), which was phosphorylated by Clb2-Cdk1 in vitro and in vivo. Accordingly, the anti-S424-P antibody specifically recognized Hof1 but not Hof1-S424A (Supplemental Fig. S4). Analysis of Hof1-3HA immunoprecipitated from various stages of the cell cycle showed that Cdk1 phosphorylated S424 during mitosis (Supplemental Fig. S6). Because we were unable to obtain phospho-specific antibodies for Cdc5- and Dbf2-Mob1-specific sites, we constructed phosphorylation inhibitory mutants (in which the relevant threonine/serine residues had been changed to alanine) for Cdc5 (Hof1-cdc5A) and Dbf2Mob1 (Hof1-dbf2A) and asked whether the mutations diminished the degree of Hof 1 hyperphosphorylation in cells lacking Grr1. In parallel, we analyzed Cdk1 phospho-inhibitory Hof1-Cdk1A mutations (Fig. 3E). In contrast to Hof1, which was hyperphosphorylated in grr1s cells, Hof1-cdc5A, Hof1-dbf2A, and Hof1-cdk1A accumulated faster-migrating hypophosphorylated forms (Fig. $3 \mathrm{E}$, asterisk). Thus, mitotic phosphorylation on the Cdk1, Cdc5, and Dbf2-Mob1 sites identified here did indeed contribute to Hofl phosphorylation in vivo. Since more 
than one kinase is involved in Hof1 phosphorylation, hyperphosphorylated forms did not completely disappear in hof1-cdc5A, hof1-dbf2A, and hof1-cdk1A mutants. Collectively, the data show that Hof1 is an in vivo substrate of Clb2-Cdk1, Cdc5, and Dbf2-Mob1 kinases. Phosphorylation of Hof 1 by Dbf2 has been suggested previously (Vallen et al. 2000).

\section{Phosphorylation of S517 between the RLS and SH3 domains is critical for Hof1 function}

It is well established that Cdk1 acts as a priming kinase for Cdc5 (Asano et al. 2005; Yoshida et al. 2006; Crasta et al. 2008). This was also the case for Hof1, as Hof1 that had been phosphorylated previously by Clb2-Cdk1 was a better substrate for Cdc5 (Supplemental Fig. S4). Furthermore, the interaction of Cdc5 with Hof1-cdk1A in the yeast two-hybrid system was much weaker than its interaction with wild-type Hof1 (Supplemental Fig. S4). Thus, an important function of mitotic $\mathrm{Cdk} 1$ is to regulate the ability of Cdc5 to dock with and phosphorylate Hof1.

To investigate the role of Dbf2 phosphorylation for Hof1 function, we analyzed hof1-dbf2A phospho-inhibi- tory mutants but observed no major defects in AMR contraction, Inn1 localization, and septum formation (data not shown). Hof1 is not essential in the S288C background, since it belongs to one of four functionally redundant pathways (represented by Hof1, Cyk3, Myo1, and Inn1) that are important for cytokinesis (Korinek et al. 2000; Tolliday et al. 2001). Consequently, cells are able to survive if a single gene representing either of these pathways is deleted, but are unviable as soon as two or more pathways are inactivated. We therefore exploited this genetic background to test whether phosphorylation of Hof 1 becomes essential following inactivation of any of the other cytokinetic pathways. We found that blocking all Dbf2 phosphorylation sites (hof1-dbf2A) or only Ser 517, Ser 533, and Ser 563 (substitution of a single residue or a combination of residues with alanine) caused sickness or lethality in the absence of CYK3 but not MYO1 or INN1 (Fig. 4A,B; Supplemental Fig. S5). Thus, phosphorylation of Hof1 at S517, S533, and S563 is important for the function of Hof1 in a pathway parallel to CYK3.

Ser 517, Ser 533, and Ser 563 are located in between the RLS and SH3 domains of Hof1 (Fig. 4A). Interestingly, while S533 and S563 are phosphorylated by Dbf2-Mob1, S517 was phosphorylated by Dbf2-Mob1 and Cdc5. Using

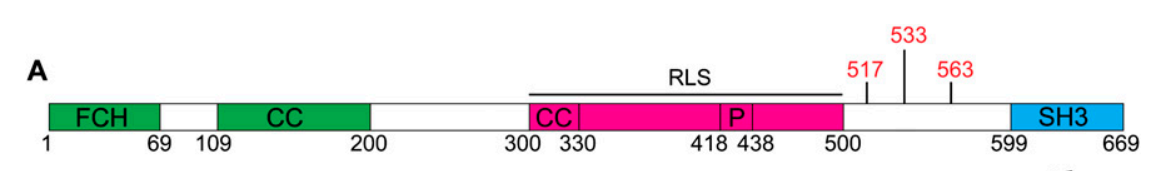

B B C
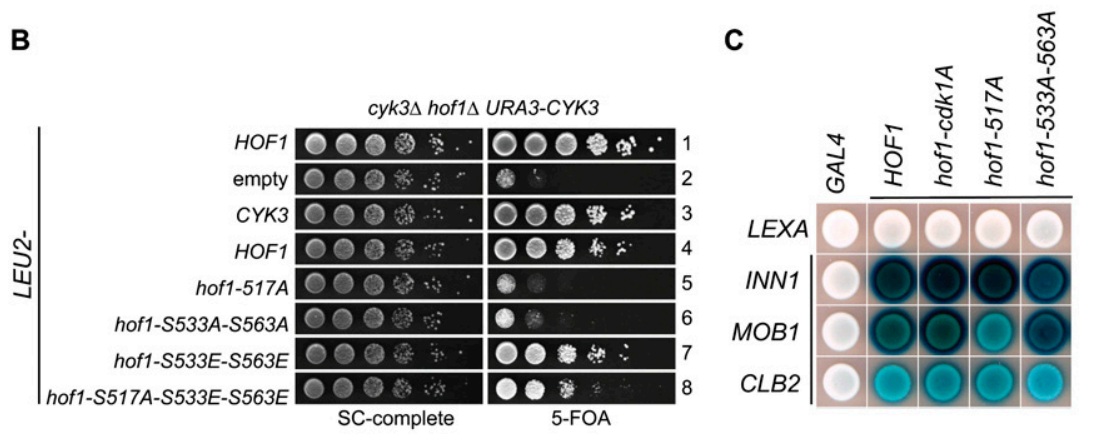

D

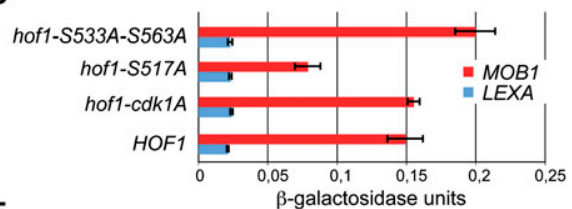

E
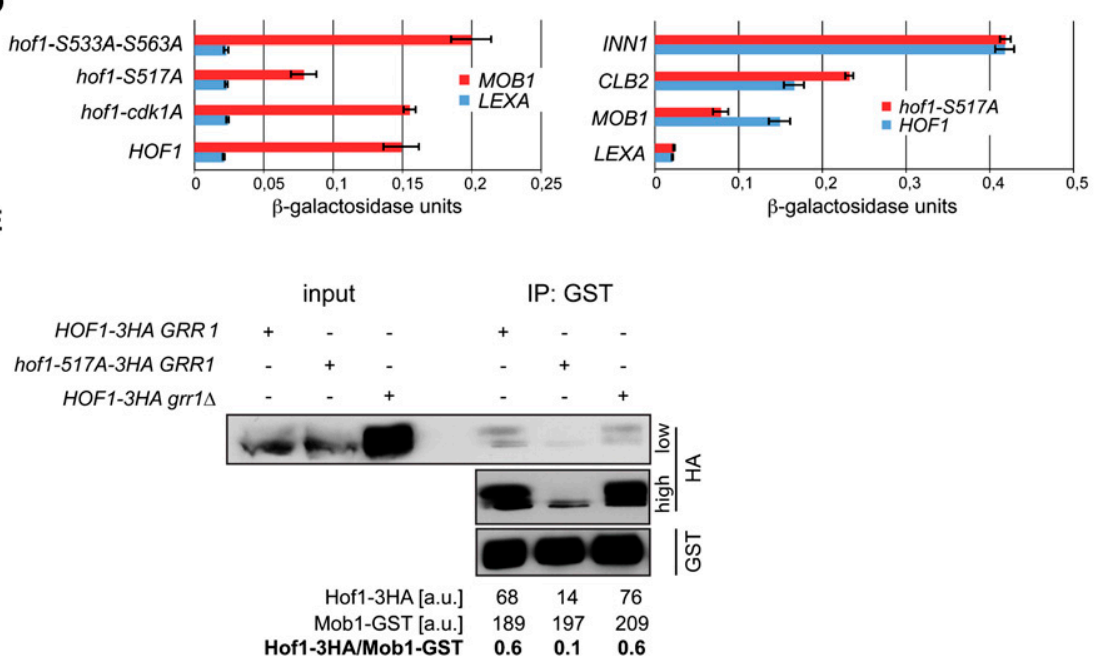

Figure 4. Hofl phosphorylation is important for its function. (A) Schematic representation of Hofl (as in Fig. 1A) showing the position of essential phosphorylation sites (depicted in red). (B) Serial dilutions of cyk3A hof1A URA3-CYK3 cells carrying the indicated LEU2-based plasmids. Cells were spotted on SC-complete and 5-FOA plates. Only URA3-negative cells grow on 5 -FOA; i.e., no growth denotes growth lethality upon loss of URA3-based CYK3 plasmid. $(C)$ Yeast two-hybrid interactions between the indicated LEXA and GAL4 gene fusions. Development of a blue color indicates interaction. $(D)$ Quantification of $C ; \beta$-galactosidase units are given in arbitrary units. (E) Pull-down assay using purified Dbf2-Mob1-GST complexes (immobilized on sepharose beads) incubated with yeast cell lysates of the indicated cell backgrounds. Immunoblots were detected using anti-HA (low and high exposure times are shown) and anti-GST antibodies. Signal intensities (arbitrary units) and the ratio of Hof1-3HA or Hof1-S517A-3HA bound to Mob1-GST are indicated. 
the yeast two-hybrid system, we found that Hof1-S517A interacted less efficiently with Mob1 than either Hof1, Hof1-S533A, or Hof1-S563A (Fig. 4C,D). The decreased interaction between Hof1-S517A and Mob1 was not caused by a reduction in Hof1-S517A protein stability, as Hof1-S517A and Hof1 interactions with Inn1 and Clb2 were indistinguishable from one another (Fig. 4C,D). Thus, binding of Hof1 to Mob1 might depend on phosphorylation of Hof1-S517.

To further confirm that phosphorylation of S517 promotes the binding of Dbf2-Mob1 to Hof1, pull-down experiments were performed with immobilized GSTDbf2-Mob1 complexes and yeast cell lysates of cells expressing HOF1-3HA or hof1-S517A-3HA (Fig. 4E). Hyperphosphorylated Hof1-3HA but not Hof1-S517A3HA bound to GST-Dbf2-Mob1 (Fig. 4E). Similar results were obtained for grr1s cells, in which hyperphosphorylated Hof1 forms accumulated (Fig. 4E; data not shown). Thus, phosphorylation of S517 is critical for the binding of Hof1 to the Dbf2-Mob1 kinase complex.

Given that phosphorylated S517 promotes the recruitment of Dbf2-Mob1 kinase, we hypothesized that blocking S517 phosphorylation might diminish the Dbf2Mob1-dependent phosphorylation at Ser 533 and Ser 563. If this view were to be correct, we would expect to be able to circumvent the lethality of hof1-S517A in cyk3s cells by mimicking phosphorylation at Ser 533 and Ser 563. Indeed, hof1-S517A-S533E-S563E cyk3A cells were viable, whereas hof1-S517A cyk3s double mutants were not (Fig. 4B, lanes 5,8). Thus, mimicking the constitutive phosphorylation of the Dbf2 sites S533 and S563 reconstituted functionality of hof1-S517A in the cyk3s background. These data are consistent with the notion that phosphorylation at S517 is a prerequisite for phosphorylation of S533 and S563 of Hof1 by Dbf2-Mob1 in vivo.

Together, our data show that phosphorylation of the serine residues at positions 517,533 , and 563 within the region between the RLS and SH3 domains of Hof1 is important for Hofl function during cytokinesis.

\section{Cdc5 and Dbf2-Mob1 colocalize sequentially with Hof1 at the bud neck}

To get a clearer insight into the timing of the Cdc5- and Dbf2-Mob1-dependent phosphorylation of Hof1, we analyzed the colocalization of Hof1 with Cdc5 and Dbf2Mob1 at the bud neck. In late anaphase, Hof1-mCherry localized at the bud neck in a septin-like manner, while GFP-Dbf2 localization was restricted to spindle pole bodies (SPBs) (Fig. 5A, panel 1). When GFP-Dbf2 appeared weakly at the bud neck at the medial ring, Hof1-mCherry started to accumulate at the medial plane (Fig. 5A,E, panel 3). After Hof1-mCherry had completely merged into one single ring, it colocalized with GFP-Dbf2 (Fig. 5A,E, panels 4,5). Eventually, the Hof1-mCherry transformed into a single dot as a consequence of AMR contraction, while the GFP-Dbf2 ring signal remained unchanged (Fig.
A

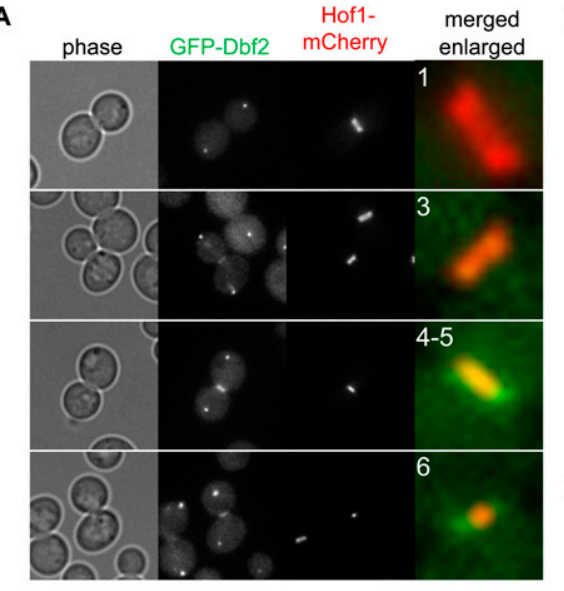

C

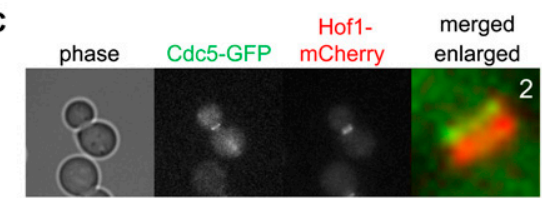

E

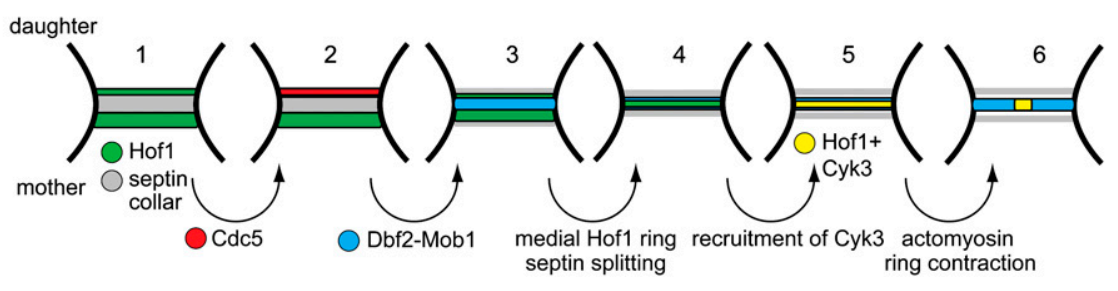

B Cyk3- merged

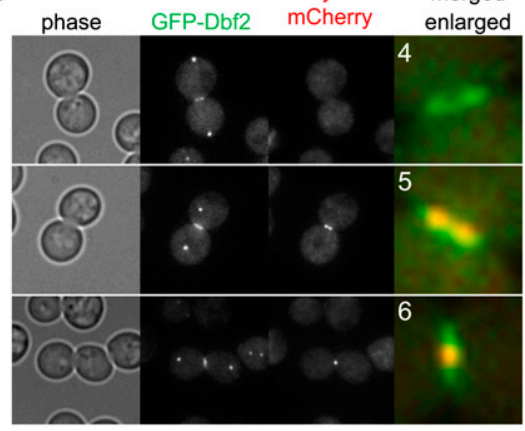

D

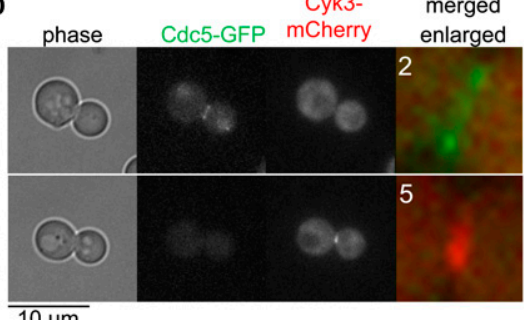

$\overline{10 \mu \mathrm{m}}$ septin splitting
Figure 5. Hof1 colocalizes with Cdc5 and Dbf2-Mob1 at the bud neck. Cycling cells of GFP-DBF2 HOF1-mCherry $(A)$, GFP-DBF2 Cyk3-mCherry (B), CDC5-GFP HOF1-mCherry $(C)$, and CDC5-GFP CYK3$m$ Cherry $(D)$ were analyzed by fluorescence microscopy. The merged images in $A-D$ represent enlargements of the bud neck area. Please note that GFP-Dbf2 also localizes at the SPBs (dot-like signals). (E) Overview of the timely localization of Hofl, Cdc5, Dbf2-Mob1, and Cyk3 at the bud neck. Steps 1-6 are exemplified by cells shown in $A-D$. Hofl localizes at the bud neck (septin-like staining) prior to Dbf2Mob1 (A, panel 1), and relocalizes to a single medial ring concomitantly with the recruitment of Dbf2-Mob1 to the bud neck (A, panels 3-5). (A, panel 6) Hof1 contracts with the AMR, whereas Dbf2 does not. $(B$, panels 4,5) The late cytokinetic marker Cyk3 gets recruited to the bud neck after Dbf2. (B, panel 6) Cyk3 contracts with the AMR, whereas Dbf2 stays as a ring at the bud neck. Hof 1 colocalizes with $\mathrm{Cdc} 5$ at the septin scaffold (C, panel 2), but Cdc5 is not part of the contractile AMR, since it never colocalizes with $\operatorname{Cyk} 3(D$, panels 2,5). 
5A,E, panel 6). Similar results were obtained for Hof1mCherry and Mob1-GFP (data not shown). Thus, Dbf2Mob1, unlike Hof1, does not contract with the AMR. This conclusion was confirmed by comparing GFP-Dbf2 with Cyk3-mCherry. Cyk3-mCherry is targeted to the bud neck in late anaphase and contracted with the AMR, forming a dot-like staining at the central region of the GFP-Dbf2 signal at the bud neck (Fig. 5B,E). We conclude that Dbf2-Mob1 colocalizes with Hof1 concomitantly with the translocation of Hof1 from septins to the AMR, yet Dbf2-Mob1 is not associated with the contractile AMR.

Cdc5 localizes at the bud neck in anaphase (Song et al. 2000). Our analysis revealed that Cdc5-GFP colocalized preferentially with the Hofl-mCherry ring that was closer to the daughter side of the bud neck (Fig. 5C,E). The significance of this observation is presently unclear. It is most likely that Cdc5-GFP dissociated from, or is degraded at the bud neck prior to, AMR contraction, because Cdc5 could never be observed at the neck when the Hof 1 or Cyk3 rings were contracting (Fig. 5D). Thus, Cdc5 colocalizes with Hof 1 at the bud neck prior to Dbf2Mob1 (Fig. 5E). This is consistent with our genetic data showing that Cdc5 acts upstream of Dbf 2 in phosphorylating Hof1.

Hof1 phosphorylation is required to release Hof1 from the septin scaffold and for recruitment to the AMR

We next investigated the impact of Dbf2-Mob1-dependent phosphorylation on Hof 1 function. We made use of the conditional lethal $d b f 2-2$ mutant carrying a gene deletion for the Dbf2-related kinase Dbf20, which has functional redundancy with Dbf2 (Meitinger et al. 2010). In $d b f 2-2 d b f 20 \Delta$ cells, we examined the localization of Hof 1 mutants in which the specific phosphorylation sites for Dbf2 (Supplemental Table S1) were mutated to alanine (Hof1-dbf2A) or glutamic acid (Hof1-dbf2E) to either block or mimic phosphorylations, respectively. While Hof1-dbf2A-GFP mutants colocalized with septins in the same way as Hof1-GFP, the phosphomimetic Hof1dbf2E-GFP translocated to the medial ring (Fig. 6A; data not shown). The change in recruitment pattern from septins to the medial ring was not dependent on Hofl degradation, since cellular Hof1-dbf2E-GFP protein levels were comparable with those of Hof1-GFP (Fig. 6B). Identical results were obtained for conditional lethal mob1-67 cells (data now shown). Furthermore, the relocation of Hof1-dbf2EGFP was not due to splitting of the septin ring (Fig. 6A) and was independent of the integrity of the actin cytoskeleton, since Hof1-dbf2E-GFP was maintained at the medial ring even after cells had been treated with the actin-depolymerizing drug latrunculin A (Supplemental Fig. S6). Thus, mutation to mimic constitutive phosphorylation of Hof1 at Dbf2 target sites bypasses the requirement of Dbf2-Mob1 for Hof1 medial ring localization.

The observation that Hof1-dbf2E-GFP exhibited a reduced colocalization with septins (Fig. 6A) prompted us to test whether the interaction between Hofl and septins was influenced by Dbf2 phosphorylation. In a two-hybrid screen, we found that the interaction of Hof1-dbf2E with Cdc10 and other septins was significantly reduced, while the same Hof1-dbf2E molecule interacted with Mob1 to the same extent as both Hof1-dbf2A and Hof1 (Fig. 6C,D; data not shown). Our attempts to assess this interaction in pull-down experiments failed, presumably because of the complexity of septin ring architecture.

Collectively, our data suggest that phosphorylation of Hof1 by Dbf2-Mob1 weakens the association between Hof1 and septins while promoting Hofl recruitment to the AMR in late mitosis.

Inactivation of the Hof1 SH3 or F-BAR domain cooperates with Dbf2-Mob1 to promote medial ring recruitment of Hof1

During the course of our experiments, we noticed that the behavior of hof1-dbf2E was reminiscent of that of the hof1-W637A and hof1-300-669 mutants in which SH3 and F-BAR domain functions were compromised, respectively. These mutants showed reduced recruitment to septins and premature recruitment to the medial rings of anaphase cells (cf. Figs. 6E-G and 1A-C). This observation led us to investigate the localization of Hof1-W637AGFP and Hof1-300-669-GFP in dbf2-2 dbf20s cells. Hof1W637A-GFP localized preferentially to the medial ring in the same way as seen for Hof1-dbf2E-GFP (Fig. 6H). We could not analyze the localization of Hof1-300-669-GFP in $d b f 2-2 d b f 20 \Delta$ cells, since this double mutant resembled $d b f 2-2 d b f 20 \Delta$ hof1 $\Delta$ cells in being lethal (Meitinger et al. 2010). Instead, we analyzed the localization of Hof1300-669-GFP in temperature-sensitive cdc15-1 mutants that arrest in late anaphase with low Dbf2 activity (Mah et al. 2001). cdc15-1 is not synthetic lethal with hof1-300669 or hof1s (Meitinger et al. 2010). Whereas Hof1-GFP stayed at the septin ring in wild-type controls, Hof1-300669-GFP was prematurely recruited to the AMR in $c d c 15-1$ cells (data not shown). We therefore reasoned that the $\mathrm{SH} 3$ domain may cooperate with the F-BAR region to hold Hofl at septins in the absence of Dbf2-Mob1 activity. Thus, our data suggest that inactivation of either the $\mathrm{SH} 3$ or F-BAR domain bypasses the requirement for Dbf2-Mob1 activity to drive Hof1 to the medial ring. The most likely mechanism by which they do this is by weakening the association between Hofl and septins.

\section{Phosphorylation mimetic mutations activate Hof1 in the absence of Dbf2 kinase activity}

We next asked whether, in the absence of Dbf2-Mob1 activity, Hof1-dbf2E was able to restore Hof1 function at the medial ring. It has been shown previously that inactivation of Dbf2-Mob1 induces cytokinetic defects in AMR contraction and septum formation. Some of these defects were based on the failure of $d b f 2-2 d b f 20 \Delta$ mutants to target Inn 1 and Cyk3 to the bud neck (Meitinger et al. 2010). Inn1 and Cyk3 are direct binding partners of Hof1 (Nishihama et al. 2009). We therefore asked whether Hof1-dbf2E was able to bypass the requirement of Dbf2-Mob1 for Inn1 and Cyk3 bud neck binding. However, neither Inn1 nor Cyk3 could be 
A

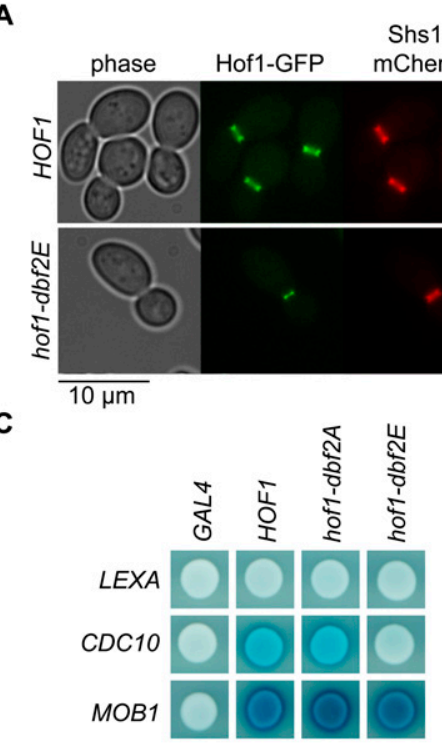

E

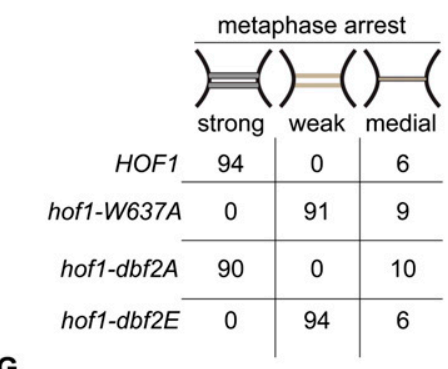

G

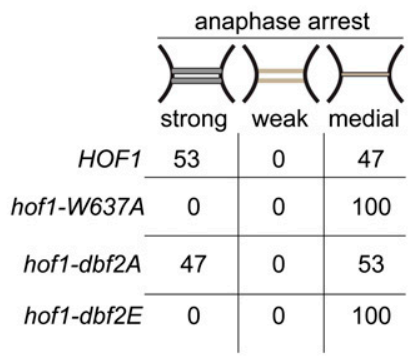

B
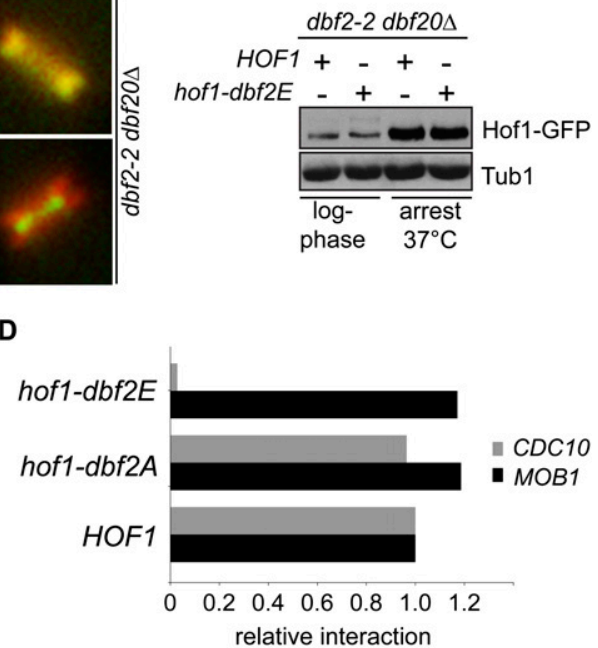

$\mathbf{F}$

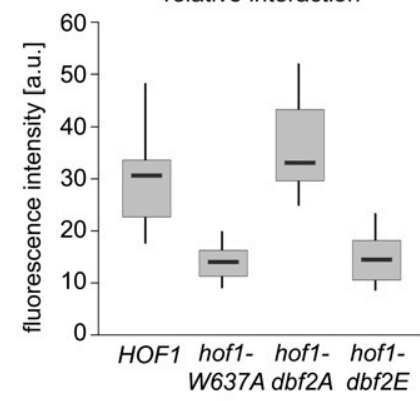

H

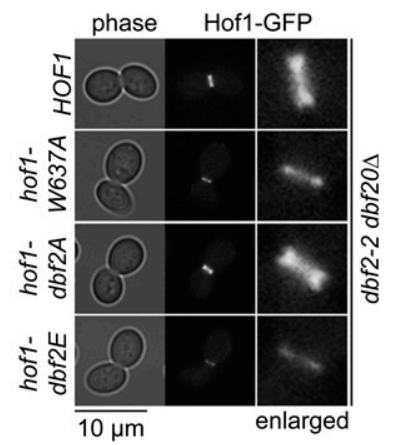

Figure 6. Phosphorylation of Hof 1 induces its rearrangement at the bud neck. (A) Localization of Hof1-GFP and Hof1dbf2E-GFP in $d b f 2-2 d b f 20 \Delta$ cells arrested for $3 \mathrm{~h}$ at $37^{\circ} \mathrm{C}$. $(B)$ Immunoblots show the levels of Hof1-GFP and Hof1-dbf2E-GFP, as indicated. Tubl served as loading control. (C) Two-hybrid interaction between the indicated LexA and Gal4 fusion proteins. (D) Quantification of $C$ representing $\beta$-galactosidase assays of three independent experiments. The graph shows the relative interaction of Hof1-dbf2A and Hof1-dbf2E with Cdc10 and Mob1. Hof1-Mob1 and Hof1-Cdc10 interactions were normalized to 1. (E) Specific bud neck localization of Hof1-GFP constructs in metaphase-arrested cells was performed as in Figure $1 .(F)$ Quantification of $E$. Fluorescence intensity is given in arbitrary units (please note that the experiments shown in $E$ and $F$ were done together with the experiments shown in Fig. 1; i.e., the values for Hof1 and Hof1W637A are the same in both figures). $(G)$ Specific bud neck localization of Hofl-GFP constructs in anaphase-arrested cells was performed as in Figure 1. $(H)$ Localization of the indicated Hofl-GFP constructs in $d b f 2-2 d b f 20 \Delta$ cells arrested for $3 \mathrm{~h}$ at $37^{\circ} \mathrm{C}$. Enlargements of the bud neck region are shown in $A$ and $H$. recruited to the AMR in hof1-dbf2E dbf2-2 dbf20 $\Delta$ cells that are arrested in late anaphase (data not shown). This indicates that the MEN regulates the recruitment of Inn1 and Cyk3 to the bud neck independently of any influence over Hof1 function.

AMR contraction does not occur in $d b f 2-2 d b f 20 \Delta$ mutants, which arrest in late anaphase with high mitotic Cdk1 activity (Vallen et al. 2000). Inactivation of mitotic Cdk1 activity in $d b f 2-2 d b f 20 \Delta$ cells, by overexpression of the mitotic Cdk1 inhibitor SIC1, leads to septin ring splitting (Meitinger et al. 2010). However, a significant slowing in the rate of AMR constriction is observed, most likely because of the lack of Dbf2 activity. We used this system to examine whether hof1-dbf2E can rescue the defect in AMR constriction caused by lack of Dbf 2 and Dbf20 activities. We monitored actin repolarization to the bud neck as a marker for reduction in Cdk1 activity and ensured that Sic1 overproduction and actin repolarization occurred with similar timing in $d b f 2-2 d b f 20 \Delta$ Gall-SIC1 cells carrying wild-type or mutant forms of HOF1 (Fig. 7). Interestingly, the Hof1-dbf2E-GFP ring, together with the Myo1, constricted more quickly than the Hof1-GFP or Hof1-dbf2A-GFP ring (Fig. 7A-C; Supplemental Fig. S7). After $60 \mathrm{~min}$ of Sicl overproduction, the AMR was constricted in $40 \%$ of $d b f 2-2 d b f 20 \Delta$ hof1dbf2E-GFP cells, while only $20 \%$ of the controls had done so. Thus, phosphomimetic Hof 1 mutants partially rescued the defect in AMR constriction seen in the $d b f 2-2$ dbf20s background. The effect of Hof1-dbf2E on AMR constriction was not a mere consequence of the relocation of Hof 1 to the medial ring, because hof1-W637A-GFP cells in which Hof1-W637A-GFP prematurely localized 
A

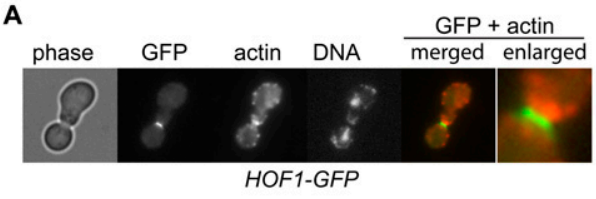

B

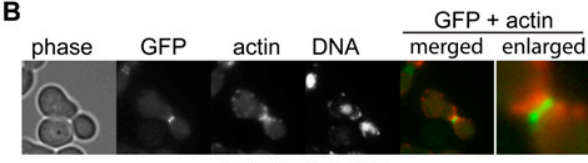

hof1-dbf2A-GFP

C

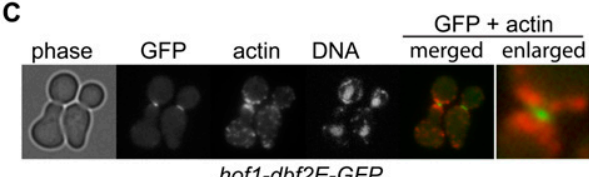

hof1-dbf2E-GFP

D

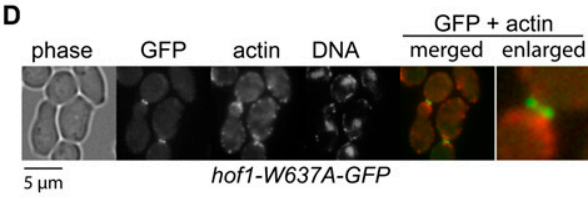

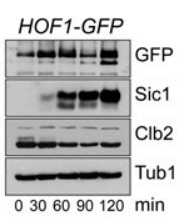

hof1-dbf2A-GFP

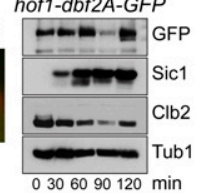

hof1-dbf2E-GFP

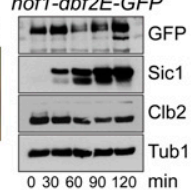

hof1-W637A-GFP
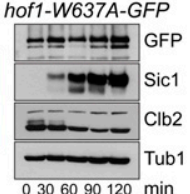
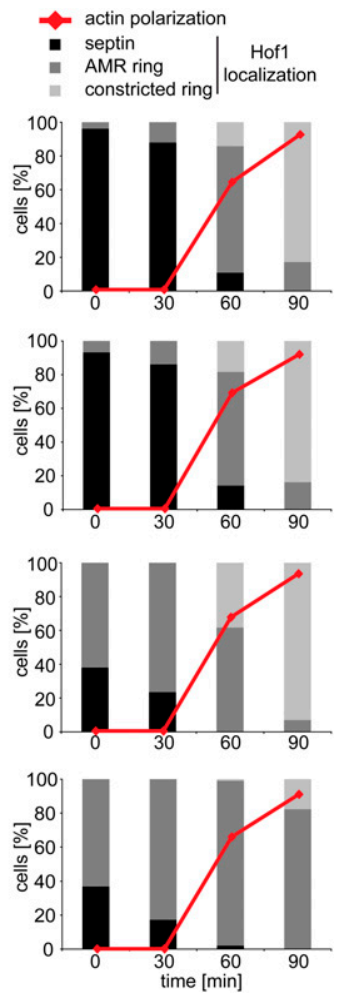

Figure 7. Hof1 phosphomimetic mutations in Dbf2 sites partially rescue $d b f 2-2$ dbf20s-dependent cytokinesis defects. Cells of the indicated genotypes were arrested in G1 at $23^{\circ} \mathrm{C}$ with $\alpha$-factor. Cells were released in nocodazole at $37^{\circ} \mathrm{C}$ to promote metaphase arrest and inactivation of Dbf2-2. After release from metaphase, overexpression of SIC1 was induced by addition of galactose to the culture medium to overcome the mitotic exit defects of $d b f 2-2 d b f 20 \Delta$ cells. Samples were taken every 30 min to monitor Hof1 localization and actin repolarization. One representative cell (taken from time point $60 \mathrm{~min}$ ) is shown in $A-D$. The levels of Hofl-GFP, Sic1, and Clb2 were monitored by immunoblotting using anti-GFP, anti-Sic1, and anti-Clb2 antibodies. Tub1 served as a loading control. The graphs indicate the percentage of cells $(n=100-150)$ showing actin repolarization at the bud neck and Hof1-GFP at septins, at the AMR ring, or as a contracted ring. to the medial ring in a manner that is comparable with that seen for Hof1-dbf2E-GFP formed a very stable AMR ring that did not contract in most cells (Fig. 7D). Together, our data suggest that both phosphorylation of Hof1 by Dbf2-Mob1 and a functional SH3 domain are required for AMR constriction.

\section{Discussion}

The conserved F-BAR protein Hof1 plays an essential role in the regulation of cytokinesis in budding yeast. Here, we investigated the regulation of Hof1 during mitosis and report that three different mitotic kinases phosphorylate Hof1 to regulate its relocalization from septins to the medial AMR to promote cytokinesis: Cdk1, the polo-like kinase Cdc5, and the MEN kinase complex Dbf2-Mob1.

\section{Hof1 is a multifunctional protein}

AMR contraction and extension of the primary septum are interdependent processes that must be coordinated to promote efficient cytokinesis. Hof1 is a multifunctional protein that might link these two processes. Ultrastructural analysis of hof $1 \Delta$ cells shows that, although cells were able to form a short primary septum, the septum did not extend, but was surrounded by a thick layer of secondary septum material (Fig. 2). The lack of primary septum extension might account for the asymmetric contraction of the AMR and the narrowing of the bud neck by the expanding secondary septum in hof1s cells. Hof1 both colocalizes and copurifies with the AMR (Lippincott and Li 1998; Young et al. 2010), raising the question as to whether Hof 1 forms a linker between the expanding primary septum and components of the contractile AMR. Hofl is also required to drive repolarization of actin patches to the bud neck (Meitinger et al. 2010).

How is Hof 1 able to perform all of these functions as cells advance through the cell cycle? Hofl has an F-BAR domain at its $\mathrm{N}$ terminus. This domain has been shown to bind and deform membranes in a variety of different cellular contexts and species (Shimada et al. 2007; Reider et al. 2009; Wang et al. 2009). Although the F-BAR domain of Hof1 has not yet been formally shown to bind directly to membranes, its deletion caused defective AMR contraction (Fig. 2). Hof1 also contains an SH3 domain at the $\mathrm{C}$ terminus that has been shown to bind to a variety of PXXP motif-rich proteins, including Inn 1 and Cyk3 (Tonikian et al. 2009), which, together with Hof1, play a role in coordinating septum formation and/or extension (Jendretzki et al. 2009; Nishihama et al. 2009). Interestingly, deletion of the SH3 domain from Hof1 did not affect AMR contraction (Fig. 2), yet did compromise viability in the absence of INN1 and MYO1. Thus, the function of the Hof1 SH3 domain acts in parallel to Inn1 and Myo1 to regulate cytokinesis. In addition, we established that the central unstructured region of Hofl, the RLS, governs the ability of Hof1 to bind to the medial ring. Our data suggest that the RLS is required for AMR contraction (Fig. 2).

\section{Hof1 is regulated by phosphorylation}

The complexity of Hof 1 function has previously compromised our ability to address its regulation. Hofl protein 
levels fluctuate in a cell cycle-dependent manner, increasing in the G1/S phase and decreasing with mitotic exit, most likely after AMR contraction. Here, we show that the mitotic kinase Cdk1 (Clb2-Cdc28), the polo-like kinase Cdc5, and the Dbf2-Mob1 complex phosphorylate Hof1 in vitro and in vivo. Using phospho-specific antibodies, we show that mitotic Cdk1 preferentially phosphorylates Hof1 during mitosis. Phosphorylation of Hof1 by Cdk1 primed it for subsequent phosphorylation by Cdc5 in vitro. The function of mitotic Cdk1 in vivo, however, is less clear, as phospho-blocking or phosphomimetic mutants in the Cdk1 sites had no impact on Hof1 function and localization (data not shown), suggesting that other kinases might functionally overlap with Cdk1 in this case. Several lines of evidence suggest that phosphorylation of Hof 1 by Cdc5 at Ser 517 facilitates the binding of Hof1 to Mob1. First, Hof1-S517A mutants interacted less efficiently with Mob1. Second, although we cannot exclude the possibility that Hof 1 phosphorylation also takes place in the cytoplasm, Hofl-Cdc5 colocalized at the bud neck prior to Hof1-Dbf2-Mob1. Third, while hof1-S517A cells were unable to grow in the absence of cyk3s, mutations in Hof1 that mimicked Dbf2-Mob1 phosphorylation bypassed this lethality. We therefore propose that Cdc5 might work upstream of Dbf2-Mob1 in Hof1 regulation.

What role does Dbf2-Mob1 play in Hof1 regulation? Functional analysis of phosphorylation site mutants together with domain localization studies, strongly suggest that Dbf2-Mob1 is involved in regulating the recruitment of Hof 1 to the medial ring during mitotic exit (Fig. 8). From the earliest stages of the cell cycle, Hof1 associates with the septins. The fact that Hof1 RLS alone did not bind to septins but did colocalize with the medial AMR in late anaphase indicates that septin binding is not required to promote the cell cycle-dependent association of Hof1 with the AMR. Full-length Hof1 translocates from septins to the AMR in a Dbf2-Mob1-dependent manner (Fig. 6), suggesting that there is an important regulatory step occurring when the Hof 1 F-BAR and SH3 domains are present. The essential Dbf2-Mob1 phosphorylation sites in Hof1 lie between the RLS and SH3 domains. Furthermore, the introduction of mutations that constitutively mimic phosphorylation of Hof1 by Dbf2-Mob1 was sufficient to drive Hof1 from septins to the medial ring in the absence of Dbf2-Mob1 activity. Although our data show that Dbf2-Mob1 plays an important role in controlling the translocation of Hof 1 from septins to the AMR through Hof1 phosphorylation, we cannot completely exclude that additional mechanisms regulate Hof1 localization, as Hof1-dbf2A localized at the AMR in wild-type cells.

\section{Model for Hof1 regulation}

We propose an "inhibition model" for the regulation of Hof1 (Fig. 8). According to this model, Hof1 stays inactive at the bud neck as a consequence of an association with the septin scaffold. The binding of Hof1 to septins depends on the F-BAR and SH3 domains, since deletion of either domain caused premature relocalization of Hof 1 to the AMR (Figs. 1, 6). On the other hand, Hof1 binding to the AMR depends on the RLS, which is located between the F-BAR and SH3 domains. It is thus possible that interaction between the F-BAR and SH3 domains and the septins might mask RLS motifs, preventing them from binding to the AMR. Alternatively, both the F-BAR and SH3 domains might interact directly with the RLS, thereby preventing its interaction with the AMR. Autoinhibition of multidomain proteins by covering interaction motifs through a folding back mechanism is frequently observed (Nezami et al. 2006; Bajorek et al. 2009). F-BAR proteins

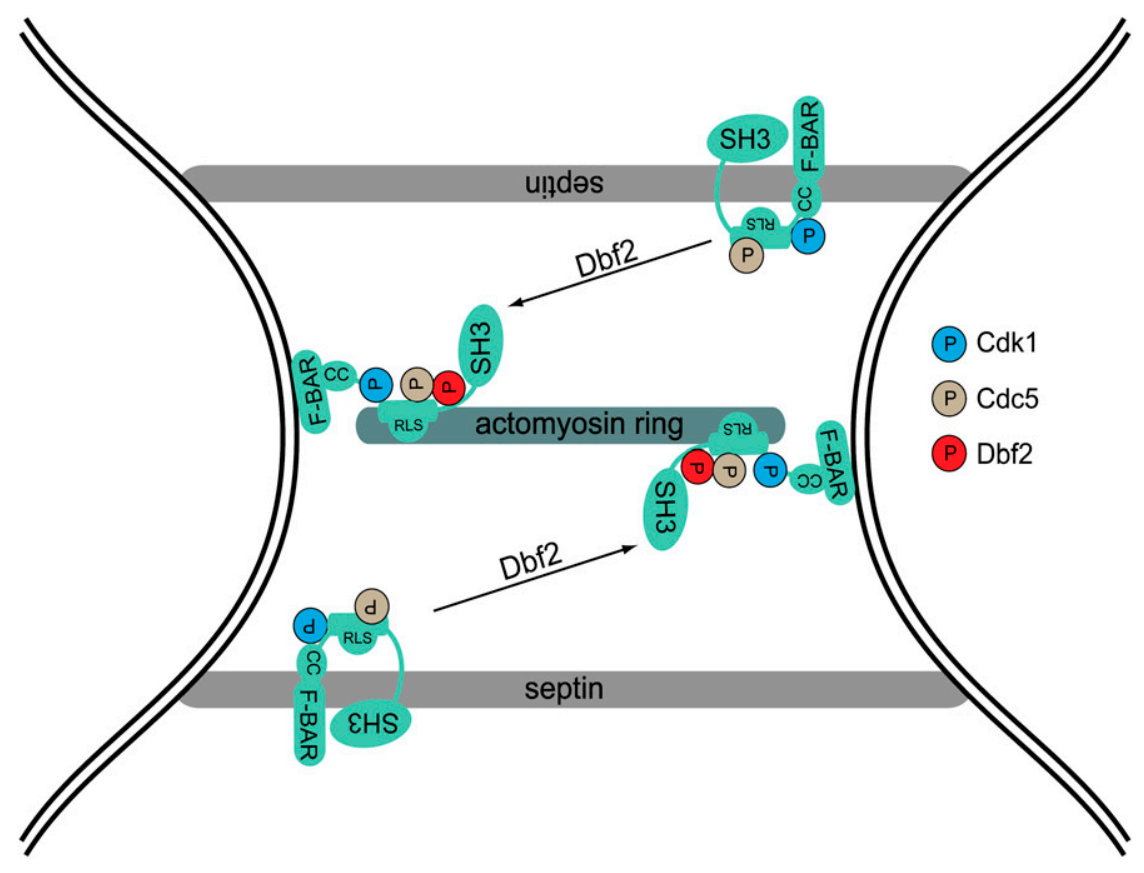

Figure 8. Model for Hofl regulation by phosphorylation. The F-BAR and SH3 domains contribute to Hofl's association with septins during most phases of the cell cycle. In late mitosis, the specific association of Hof1 with the septin scaffold gets resolved after phosphorylation of Hof 1 by Dbf2-Mob1. Phosphorylated Hof1 binds to the medial ring and, together with Cyk3 and Inn1, coordinates AMR contraction with primary septum formation. 
were shown recently to be regulated through an autoinhibition mechanism (Rao et al. 2010; Roberts-Galbraith et al. 2010). It is thus tempting to propose an autoinhibition model for Hof1 that might be based on intramolecular interactions. However, we cannot exclude the probability of trans-inhibition.

The release of Hof 1 from septins must be subject to cell cycle-dependent control to ensure that cytokinesis is initiated at the right point in the cycle. We established that Dbf2-Mob1-mediated phosphorylation mimics the deletion of the F-BAR or SH3 domains in driving the release of Hof 1 from the septins, thereby promoting Hof 1 recruitment to the AMR. Since both the F-BAR and SH3 domains are essential during cytokinesis, it is unlikely that phosphorylation inactivates these domains. The identity of the components that recruit the RLS domain of Hof 1 to the medial ring remains to be established. Inn1 and Cyk3 are recruited to the AMR after Hof1, and therefore cannot be responsible for its recruitment. Interestingly, Hofl RLS was recruited to the medial ring in a cell cycle-dependent manner, suggesting that either a late component of AMR or a cell cycle-regulated posttranslational modification of an early AMR component recruits Hofl to the medial ring.

The orthologs of Hof1 in fission yeast and human cells-Cdc15 and PSTPIP, respectively-associate with the site of cell division (Fankhauser et al. 1995; Spencer et al. 1997). PSTPIP is involved in the regulation of actincytoskeleton interactions, while fission yeast Schizosaccharomyces pombe Cdc15 participates in the formation of the contractile ring. Both Cdc15 and PSTPIP are regulated by phosphorylation. The nature of the kinases and the molecular function of phosphorylation for the function of Cdc15 and PSTPIP during cytokinesis is not yet understood (Spencer et al. 1997; Lippincott and Li 1998; Roberts-Galbraith et al. 2009). Moreover, yeast orthologs of polo-like kinase Cdc5 (Plk1), Mob1 (MOB proteins), and Dbf2 (NDR/Lats kinase) are involved in furrow formation in mammalian cells, division plane formation in plants, and septum formation in fission yeast (Hou et al. 2004; Fabbro et al. 2005; Citterio et al. 2006). It will be interesting to investigate whether Plk1-, MOB-, and NDR/Lats-related kinases have conserved roles in the regulation of F-BAR proteins during cytokinesis in not only yeast, but also higher eukaryotes.

\section{Materials and methods}

Strains, plasmids, growth conditions, and genetic methods

Yeast strains and plasmids used in this study are listed in Supplemental Tables S2 and S3. Yeast growth conditions and media were as described (Sherman 1991). Gene deletions and epitope tagging were performed using PCR-based methods (Knop et al. 1999; Janke et al. 2004). Yeast strains were grown in yeast peptone dextrose medium containing $0.1 \mathrm{mg} / \mathrm{L}$ adenine (YPAD). Instead of dextrose, either $3 \%$ raffinose (YPAR) or a mixture of $3 \%$ raffinose and $2 \%$ galactose (YPARG) was used in experiments involving expression of genes under control of the Gall promoter. Synthetic complete (SC) media lacking corresponding amino acids were used to grow strains carrying plasmids. Loss of URA3-containing plasmids was tested using plates containing 1 $\mathrm{mg} / \mathrm{mL} 5$-fluoroorotic acid (5-FOA). To test the viability of double mutants, we used a plasmid shuffle strategy. Briefly, mutants strains containing the corresponding wild-type gene on URA3based plasmid were analyzed for growth on 5-FOA plates (select against URA3). At least six individual transformants were analyzed per double mutant, and one representative mutant is shown.

\section{Cell culture synchronization}

For synchronization of cells in the G1 phase, $10 \mu \mathrm{g} / \mathrm{mL}$ synthetic $\alpha$-factor (Sigma-Aldrich) was added to cultures in the early log phase $\left(5 \times 10^{6}\right.$ cells per milliliter) and incubated for $\sim 2.5 \mathrm{~h}$, until $>95 \%$ of the cells formed mating projections. To arrest the cells with nocodazole, $15 \mu \mathrm{g} / \mathrm{mL}$ nocodazole (Sigma-Aldrich) was added to the culture media and incubated $2-4 \mathrm{~h}$, until $>90 \%$ of the cells arrested with large buds and one DNA-stained region (DAPI staining). To provide late anaphase arrest, $2 \%$ galactose was added to the log phase culture of Gall-CLB2- $\triangle D B$ cells grown in YPAR medium.

\section{Protein methods}

Yeast protein extracts and Western blotting were performed as described (Janke et al. 2004). Antibodies were rabbit anti-GFP antibody, mouse anti-tubulin (Tub1), mouse anti-HA (clone 12CA5, Sigma), rabbit anti-Clb2, and guinea pig anti-Sic1 (Maekawa et al. 2007). The peptide-based rabbit anti-Hof1-S424-P antibody was raised in rabbits using the peptide NQSLSS(p)PSESSSS, in which (p) denotes the phosphorylated serine (Peptide Specialty Laboratories $\mathrm{GmbH}$ ). Anti-Hof1-S424-P antibodies were purified from the preabsorbed sera by affinity purification using the immobilized phophopeptide. Secondary antibodies were goat anti-mouse, goat anti-rabbit, and goat anti-guinea pig IgGs coupled to horseradish peroxidase (Jackson ImmunoResearch Laboratories).

\section{Microscopic techniques}

For fluorescence still image analysis, cells carrying GFP or Cherry fusion proteins were fixed in $4 \%$ formaldehyde for $10-$ $30 \mathrm{~min}$ before inspection. Cells were fixed with $70 \%$ ethanol and resuspended in PBS containing $1 \mu \mathrm{g} / \mathrm{mL}$ 4',6-diamino-2-phenylindole (DAPI) (Sigma) for DNA visualization (DAPI staining). For actin staining, cells were fixed for $60 \mathrm{~min}$ in $3.7 \%$ formaldehyde solution in PBS. Actin was stained with $2 \mu \mathrm{M}$ rhodaminephalloidine (Invitrogen). Live-cell imaging and quantification of fluorescence still images were performed as described (Caydasi and Pereira 2009). Specimens for electron microscopy were prepared as described (Maier et al. 2008).

\section{Protein purifications}

MBP-Bfal from Escherichia coli was purified as described previously (Geymonat et al. 2007; Maekawa et al. 2007). GST-Hof1 was purified from $E$. coli according to the manufacturer's instructions (GE Healthcare and EMD). Clb2-Cdk1, Dbf2-Mob1, and Cdc5 were purified from yeast cells as described (Ubersax et al. 2003; Geymonat et al. 2007). For mass spectrometric analysis, Hof1-3HA and Hof1-9Myc were purified from 1.6-L of culture of wild-type and grr1s cells as described in Immunoprecipitation Experiments, below.

\section{In vitro kinase assay}

In vitro kinase assays of purified Cdc5 and Dbf2-Mob1 were performed in a kinase reaction buffer containing $50 \mathrm{mM}$ Tris- $\mathrm{HCl}$ 
(pH 7.5), $1 \mathrm{mM} \mathrm{DTT}, 10 \mathrm{mM} \mathrm{MgCl}_{2}$, and $0.1 \mathrm{mM}$ ATP. Reactions using Clb2-Cdk1 contained $25 \mathrm{mM}$ HEPES (pH 7.4), $150 \mathrm{mM}$ $\mathrm{NaCl}, 10 \mathrm{mM} \mathrm{MgCl}_{2}, 0.5 \mathrm{mM}$ DTT, $5 \mathrm{mM} \mathrm{MgCl}_{2}$, and $0.1 \mathrm{mM}$ ATP. GST-Hofl purified from E. coli served as a substrate. Reactions were held for $30 \mathrm{~min}$ at $30^{\circ} \mathrm{C}$. A total of $5 \mu \mathrm{Ci}$ of $\gamma-\left[{ }^{32} \mathrm{P}\right]$ ATP $(0.05 \mathrm{nM})$ was used per radioactive kinase reaction. Radioactivity was detected using a Bas 1800 II imaging system (Fujifilm).

\section{Immunoprecipitation experiments}

Pellets from a $100-\mathrm{mL}$ yeast culture $\left(10^{7}\right.$ cells per milliliter) were lysed in a FastPrep FP120 Cell Disturber (MP Biomedicals) using acid-washed glass beads (Sigma-Aldrich). Lysis buffer contained $50 \mathrm{mM}$ Tris- $\mathrm{HCl}(\mathrm{pH} 7.5), 150 \mathrm{mM} \mathrm{NaCl}, 10 \%$ glycerol, $1 \mathrm{mM}$ EDTA, $1 \mathrm{mM}$ DTT, $350 \mu \mathrm{g} / \mathrm{mL}$ benzamidine, $100 \mathrm{mM} \beta$-glycerophophate, $50 \mathrm{mM} \mathrm{NaF}, 5 \mathrm{mM} \mathrm{NaVO}_{3}$, and complete EDTA-free protease inhibitor cocktail (Roche). Cell lysates were incubated with $1 \%$ Triton X-100 for $15 \mathrm{~min}$. Total extracts were clarified by centrifugation at $10,000 \mathrm{~g}$ for $10 \mathrm{~min}$. Hof1-3HA or Hof1-9Myc was immunoprecipitated from total extracts using anti-HA- or anti-MYC-coupled protein A-Sepharose beads (GE Healthcare). For pull-down assays, the purified immobilized Dbf2-Mob1-GST complex was incubated for $3 \mathrm{~h}$ with yeast cell extracts of HOF1$3 H A$ and hof1-S517A-3HA cells.

\section{Acknowledgments}

We are grateful to Elmar Schiebel and Steve Sedgwick for reagents, and Tanja Herrmann-Ussia for sharing purified proteins. We thank Elmar Schiebel, Iain Hagan, Jennifer Ortiz, Fouzia Ahmad, and members of G.P.'s laboratory for comments on the manuscript. F.M. is funded by the Marie Curie Grant MEXT-CT-042544. The work of G.P. is funded by the Marie Curie (MEXT-CT-042544) and Helmholtz Young Investigator (HZ-NG-111) Grants.

\section{References}

Asano S, Park JE, Sakchaisri K, Yu LR, Song S, Supavilai P, Veenstra TD, Lee KS. 2005. Concerted mechanism of Swe1/ Weel regulation by multiple kinases in budding yeast. EMBO J 24: 2194-2204.

Aspenstrom P. 2009. Roles of F-BAR/PCH proteins in the regulation of membrane dynamics and actin reorganization. Int Rev Cell Mol Biol 272: 1-31.

Aspenstrom P, Fransson A, Richnau N. 2006. Pombe Cdc15 homology proteins: regulators of membrane dynamics and the actin cytoskeleton. Trends Biochem Sci 31: 670-679.

Bajorek M, Schubert HL, McCullough J, Langelier C, Eckert DM, Stubblefield WM, Uter NT, Myszka DG, Hill CP, Sundquist WI. 2009. Structural basis for ESCRT-III protein autoinhibition. Nat Struct Mol Biol 16: 754-762.

Balasubramanian MK, Bi E, Glotzer M. 2004. Comparative analysis of cytokinesis in budding yeast, fission yeast and animal cells. Curr Biol 14: R806-R818. doi: 10.1016/j.cub. 2004.09.022.

Bardin AJ, Amon A. 2001. MEN and SIN: what's the difference? Nat Rev Mol Cell Biol 2: 815-826.

Barr FA, Gruneberg U. 2007. Cytokinesis: placing and making the final cut. Cell 131: 847-860.

Bi E. 2001. Cytokinesis in budding yeast: the relationship between actomyosin ring function and septum formation. Cell Struct Funct 26: 529-537.

Blondel M, Bach S, Bamps S, Dobbelaere J, Wiget P, Longaretti C, Barral Y, Meijer L, Peter M. 2005. Degradation of Hof1 by
SCF(Grrl) is important for actomyosin contraction during cytokinesis in yeast. EMBO J 24: 1440-1452.

Caydasi AK, Pereira G. 2009. Spindle alignment regulates the dynamic association of checkpoint proteins with yeast spindle pole bodies. Dev Cell 16: 146-156.

Citterio S, Piatti S, Albertini E, Aina R, Varotto S, Barcaccia G. 2006. Alfalfa Mob1-like proteins are involved in cell proliferation and are localized in the cell division plane during cytokinesis. Exp Cell Res 312: 1050-1064.

Crasta K, Lim HH, Giddings TH Jr, Winey M, Surana U. 2008. Inactivation of Cdh1 by synergistic action of Cdk1 and polo kinase is necessary for proper assembly of the mitotic spindle. Nat Cell Biol 10: 665-675.

Fabbro M, Zhou BB, Takahashi M, Sarcevic B, Lal P, Graham ME, Gabrielli BG, Robinson PI, Nigg EA, Ono Y, et al. 2005. Cdk1/Erk2- and Plk1-dependent phosphorylation of a centrosome protein, Cep55, is required for its recruitment to midbody and cytokinesis. Dev Cell 9: 477-488.

Fankhauser C, Reymond A, Cerutti L, Utzig S, Hofmann K, Simanis V. 1995. The $S$. pombe cdc15 gene is a key element in the reorganization of F-actin at mitosis. Cell 82: 435-444.

Frenz LM, Lee SE, Fesquet D, Johnston LH. 2000. The budding yeast Dbf2 protein kinase localises to the centrosome and moves to the bud neck in late mitosis. J Cell Sci 113: 33993408.

Geymonat M, Spanos A, Sedgwick SG. 2007. A Saccharomyces cerevisiae autoselection system for optimised recombinant protein expression. Gene 399: 120-128.

Hammarton TC, Lillico SG, Welburn SC, Mottram JC. 2005. Trypanosoma brucei MOB1 is required for accurate and efficient cytokinesis but not for exit from mitosis. Mol Microbiol 56: 104-116.

Hou MC, Guertin DA, McCollum D. 2004. Initiation of cytokinesis is controlled through multiple modes of regulation of the Sid2p-Mob1p kinase complex. Mol Cell Biol 24: 32623276.

Hwa Lim H, Yeong FM, Surana U. 2003. Inactivation of mitotic kinase triggers translocation of MEN components to mother-daughter neck in yeast. Mol Biol Cell 14: 4734-4743.

Janke C, Magiera MM, Rathfelder N, Taxis C, Reber S, Maekawa H, Moreno-Borchart A, Doenges G, Schwob E, Schiebel E, et al. 2004. A versatile toolbox for PCR-based tagging of yeast genes: new fluorescent proteins, more markers and promoter substitution cassettes. Yeast 21: 947-962.

Jendretzki A, Ciklic I, Rodicio R, Schmitz HP, Heinisch JJ. 2009. Cyk3 acts in actomyosin ring independent cytokinesis by recruiting Inn1 to the yeast bud neck. Mol Genet Genomics 282: $437-451$.

Knop M, Siegers K, Pereira G, Zachariae W, Winsor B, Nasmyth K, Schiebel E. 1999. Epitope tagging of yeast genes using a PCR-based strategy: more tags and improved practical routines. Yeast 15: 963-972.

Korinek WS, Bi E, Epp JA, Wang L, Ho J, Chant J. 2000. Cyk3, a novel SH3-domain protein, affects cytokinesis in yeast. Curr Biol 10: 947-950.

Lippincott J, Li R. 1998. Dual function of Cyk2, a cdc15/PSTPIP family protein, in regulating actomyosin ring dynamics and septin distribution. J Cell Biol 143: 1947-1960.

Maekawa H, Priest C, Lechner J, Pereira G, Schiebel E. 2007. The yeast centrosome translates the positional information of the anaphase spindle into a cell cycle signal. J Cell Biol 179: 423-436.

Mah AS, Jang J, Deshaies RJ. 2001. Protein kinase Cdc15 activates the Dbf2-Mob1 kinase complex. Proc Natl Acad Sci 98: 7325-7330.

Mah AS, Elia AE, Devgan G, Ptacek J, Schutkowski M, Snyder M, Yaffe MB, Deshaies RJ. 2005. Substrate specificity analysis of 
protein kinase complex Dbf2-Mob1 by peptide library and proteome array screening. BMC Biochem 6: 22. doi: 10.1186/ 1471-2091-6-22.

Maier P, Rathfelder N, Maeder CI, Colombelli J, Stelzer EH, Knop M. 2008. The SpoMBe pathway drives membrane bending necessary for cytokinesis and spore formation in yeast meiosis. EMBO J 27: 2363-2374.

Meitinger F, Petrova B, Lombardi IM, Bertazzi DT, Hub B, Zentgraf H, Pereira G. 2010. Targeted localization of Inn1, Cyk3 and Chs2 by the mitotic-exit network regulates cytokinesis in budding yeast. J Cell Sci 123: 1851-1861.

Nezami AG, Poy F, Eck MJ. 2006. Structure of the autoinhibitory switch in formin mDial. Structure 14: 257-263.

Nishihama R, Schreiter JH, Onishi M, Vallen EA, Hanna J, Moravcevic K, Lippincott MF, Han H, Lemmon MA, Pringle JR, et al. 2009. Role of Inn1 and its interactions with Hof1 and Cyk3 in promoting cleavage furrow and septum formation in S. cerevisiae. J Cell Biol 185: 995-1012.

Rao Y, Ma Q, Vahedi-Faridi A, Sundborger A, Pechstein A, Puchkov D, Luo L, Shupliakov O, Saenger W, Haucke V. 2010. Molecular basis for SH3 domain regulation of F-BAR-mediated membrane deformation. Proc Natl Acad Sci 107: 8213-8218.

Reider A, Barker SL, Mishra SK, Im YJ, Maldonado-Baez L, Hurley JH, Traub LM, Wendland B. 2009. Syp1 is a conserved endocytic adaptor that contains domains involved in cargo selection and membrane tubulation. EMBO J 28: 3103-3116.

Roberts-Galbraith RH, Chen IS, Wang I, Gould KL. 2009. The SH3 domains of two PCH family members cooperate in assembly of the Schizosaccharomyces pombe contractile ring. I Cell Biol 184: 113-127.

Roberts-Galbraith RH, Ohi MD, Ballif BA, Chen JS, McLeod I, McDonald WH, Gygi SP, Yates JR III, Gould KL. 2010. Dephosphorylation of F-BAR protein Cdc15 modulates its conformation and stimulates its scaffolding activity at the cell division site. Mol Cell 39: 86-99.

Sagona AP, Stenmark H. 2010. Cytokinesis and cancer. FEBS Lett 584: 2652-2661.

Sanchez-Diaz A, Marchesi V, Murray S, Jones R, Pereira G, Edmondson R, Allen T, Labib K. 2008. Inn1 couples contraction of the actomyosin ring to membrane ingression during cytokinesis in budding yeast. Nat Cell Biol 10: 395-406.

Sherman F. 1991. Getting started with yeast. Methods Enzymol 194: $3-21$.

Shimada A, Niwa H, Tsujita K, Suetsugu S, Nitta K, HanawaSuetsugu K, Akasaka R, Nishino Y, Toyama M, Chen L, et al. 2007. Curved EFC/F-BAR-domain dimers are joined end to end into a filament for membrane invagination in endocytosis. Cell 129: 761-772.

Song S, Grenfell TZ, Garfield S, Erikson RL, Lee KS. 2000. Essential function of the polo box of Cdc5 in subcellular localization and induction of cytokinetic structures. Mol Cell Biol 20: 286-298.

Spencer S, Dowbenko D, Cheng J, Li W, Brush J, Utzig S, Simanis V, Lasky LA. 1997. PSTPIP: a tyrosine phosphorylated cleavage furrow-associated protein that is a substrate for a PEST tyrosine phosphatase. J Cell Biol 138: 845-860.

Surana U, Amon A, Dowzer C, McGrew J, Byers B, Nasmyth K. 1993. Destruction of the CDC28/CLB mitotic kinase is not required for the metaphase to anaphase transition in budding yeast. EMBO J 12: 1969-1978.

Tolliday N, Bouquin N, Li R. 2001. Assembly and regulation of the cytokinetic apparatus in budding yeast. Curr Opin Microbiol 4: 690-695.

Tonikian R, Xin X, Toret CP, Gfeller D, Landgraf C, Panni S, Paoluzi S, Castagnoli L, Currell B, Seshagiri S, et al. 2009. Bayesian modeling of the yeast $\mathrm{SH} 3$ domain interactome predicts spatiotemporal dynamics of endocytosis proteins. PLOS Biol 7: e1000218. doi: 10.1371/journal.pbio.1000218.

Ubersax JA, Woodbury EL, Quang PN, Paraz M, Blethrow JD, Shah K, Shokat KM, Morgan DO. 2003. Targets of the cyclindependent kinase Cdk1. Nature 425: 859-864.

Vallen EA, Caviston J, Bi E. 2000. Roles of Hoflp, Bnilp, Bnrlp, and myolp in cytokinesis in Saccharomyces cerevisiae. Mol Biol Cell 11: 593-611.

Wang Q, Navarro MV, Peng G, Molinelli E, Goh SL, Judson BL, Rajashankar KR, Sondermann H. 2009. Molecular mechanism of membrane constriction and tubulation mediated by the F-BAR protein Pacsin/Syndapin. Proc Natl Acad Sci 106: 12700-12705.

Yabuta N, Okada N, Ito A, Hosomi T, Nishihara S, Sasayama Y, Fujimori A, Okuzaki D, Zhao H, Ikawa M, et al. 2007. Lats2 is an essential mitotic regulator required for the coordination of cell division. J Biol Chem 282: 19259-19271.

Yoshida S, Toh-e A. 2001. Regulation of the localization of Dbf2 and mob1 during cell division of Saccharomyces cerevisiae. Genes Genet Syst 76: 141-147.

Yoshida S, Kono K, Lowery DM, Bartolini S, Yaffe MB, Ohya Y, Pellman D. 2006. Polo-like kinase Cdc5 controls the local activation of Rho1 to promote cytokinesis. Science 313: 108111.

Young BA, Buser C, Drubin DG. 2010. Isolation and partial purification of the Saccharomyces cerevisiae cytokinetic apparatus. Cytoskeleton 67: 13-22. 


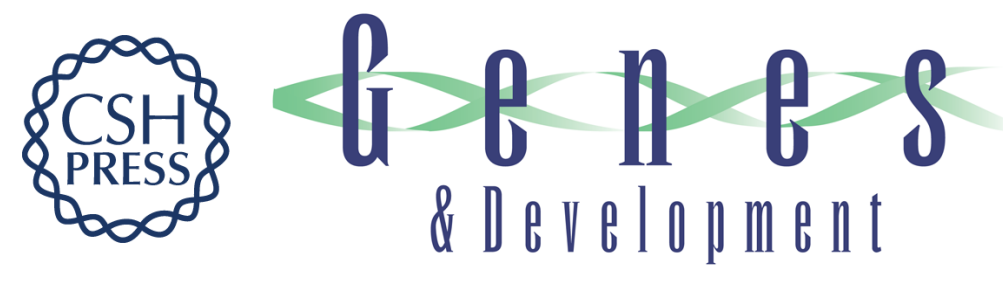

\section{Phosphorylation-dependent regulation of the F-BAR protein Hof1 during cytokinesis}

Franz Meitinger, Martin E. Boehm, Astrid Hofmann, et al.

Genes Dev. 2011, 25:

Access the most recent version at doi:10.1101/gad.622411

\section{Supplemental http://genesdev.cshlp.org/content/suppl/2011/04/12/25.8.875.DC1 Material}

References This article cites 51 articles, 17 of which can be accessed free at: http://genesdev.cshlp.org/content/25/8/875.full.html\#ref-list-1

\section{License}

Email Alerting

Receive free email alerts when new articles cite this article - sign up in the box at the top Service

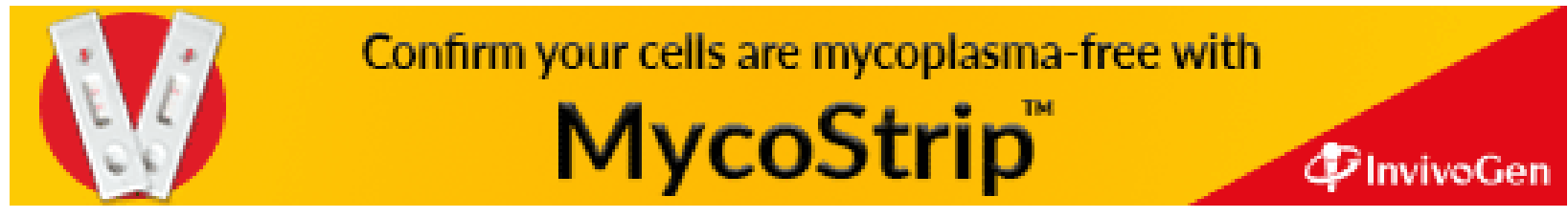

